\title{
Revascularization Following the Lateral Sliding Flap Procedure*
}

\author{
Raul G. Caffesse, $†$ Simao Kon, $\ddagger$ Walter A. Castelli§ \\ and Carlos E. Nasjleti\|
}

Accepted for publication 1 August 1983

\begin{abstract}
TWo yOUNG ADULT RHESUS MONKEYS, with an average weight of 12 pounds were used. Anesthesia with Nembutal ${ }^{\text {(i) }} 30 \mathrm{mg} / \mathrm{kg}$ of body weight was given to perform the surgeries. Artificial defects were created by raising a flap and removing about $5 \times 7 \mathrm{~mm}$ of the buccal alveolar plate and suturing the flaps exposing the alveolar crest. These defects were left untreated for 2 months. Then, mucogingival lateral sliding flaps were performed to cover the recessions. Postoperative periods of $1,9,14,21,28$ and 35 days were obtained when the animals were killed. A combined solution of Pelikan carbon black and $10 \%$ buffered formalin was perfused through the exposed and cannulated external carotid arteries to evaluate revascularization. After killing, blocks, including the operated teeth and the surrounding tissues, were fixed in $10 \%$ formalin and then partially decalcified in EDTA. Two blocks per time interval were obtained. One of the blocks was processed for regular histology, and sectioned bucco-lingually. In these sections it was found that the new attachment to the root was mediated by a combination of connective tissue attachment and a long junctional epithelium. The other blocks were cut cross-sectionally at about $1-\mathrm{mm}$ thickness. Sections were selected from three different areas: (a) at the most coronal part of the laterally displaced flap, (b) at the middle of the localized defect and (c) at the bottom of the defect. They were cleared following the Spalteholtz method. Initially, at 1-day postoperatively, a network of perfused vessels was seen marginally and the flap was well adapted to the tooth surface and the tissue bed, with a thin blood clot interposed. Healing progressed uneventfully and by 28 days the surgically treated area depicted a completely reestablished vascularization, which grew from the displaced flap, surrounding periodontal membrane and tissues. Similar results, but with faster healing, were observed in areas (b) and (c).
\end{abstract}

Lateral sliding flap procedures have received significant attention in clinical biometric studies. Histological studies, however, have not been numerous. Studies have shown that all of these procedures will heal to the tooth by a combination of connective tissue reattachment and a long junctional epithelium. ${ }^{1-3}$ Electron microscopically, hemidesmosomes and a basement lamina have been described. ${ }^{4}$ No bone regeneration is expected with any of the procedures in the area of the recession.

The purpose of the present study was to evaluate the

* This study was supported in part by the Veterans Administration.

† Professor and Chairman, Department of Periodontics, The University of Michigan School of Dentistry, Ann Arbor, MI 48109.

$\ddagger$ Visiting Associate Professor, Department of Periodontics, The University of Michigan School of Dentistry.

$\S$ Professor of Anatomy, The University of Michigan Medical School.

|| Coordinator, Dental Research Program, Veterans Administration Medical Center, Ann Arbor, MI 48105. revascularization of lateral sliding flap procedures in monkeys. A specific concern was to determine whether the periodontal membrane vasculature participated significantly in the revascularization of the surgical area.

\section{MATERIALS AND METHODS}

Two young adult Rhesus monkeys (Macaca mulatta), with an average weight of 12 pounds, were used for this study. They presented a full complement of teeth with marginal gingivitis. Under general anesthesia with pentobarbital sodium (Nembutal $\left.{ }^{(}\right), 30 \mathrm{mg} / \mathrm{kg}$ of body weight, the mouths were scaled and polished. Artificial recessions were created by raising a flap, removing about $5 \times 7 \mathrm{~mm}$ of the buccal alveolar bone, and suturing the flaps to expose the alveolar crest. Fourteen defects were created on incisors, cuspids and bicuspids. The defects had neighboring areas which were to be used later as donor sites for the lateral sliding flaps. The defects were left untreated for 2 months. 


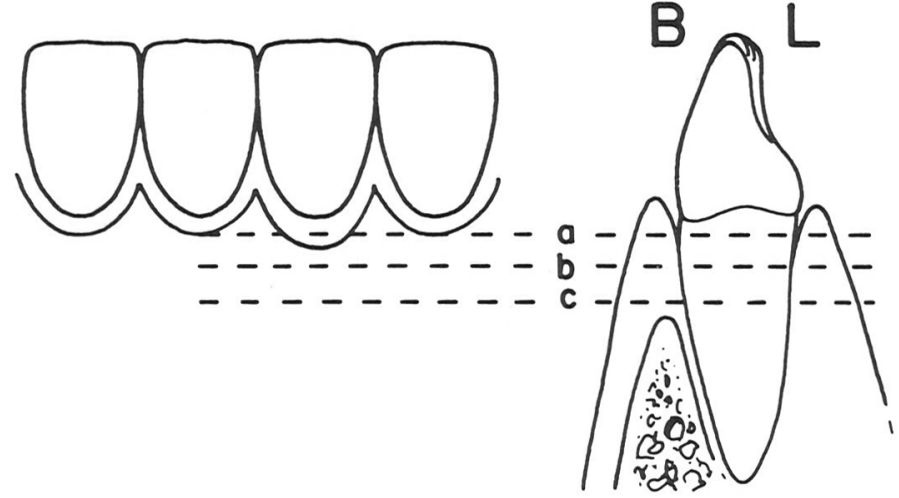

Figure 1. Diagram indicating the three cross-sectional levels selected for evaluation in the cleared specimens.

Table 1

Mean Biometric Values Recorded Before and After Surgery

\begin{tabular}{lcc}
\hline \multicolumn{1}{c}{ Variable } & Before & After* \\
\hline Pocket depth & 1.2 & 1.8 \\
Gingival recession & 3.9 & 1.8 \\
Attached gingiva & 1.4 & 4.9 \\
\hline
\end{tabular}

* At time of killing.
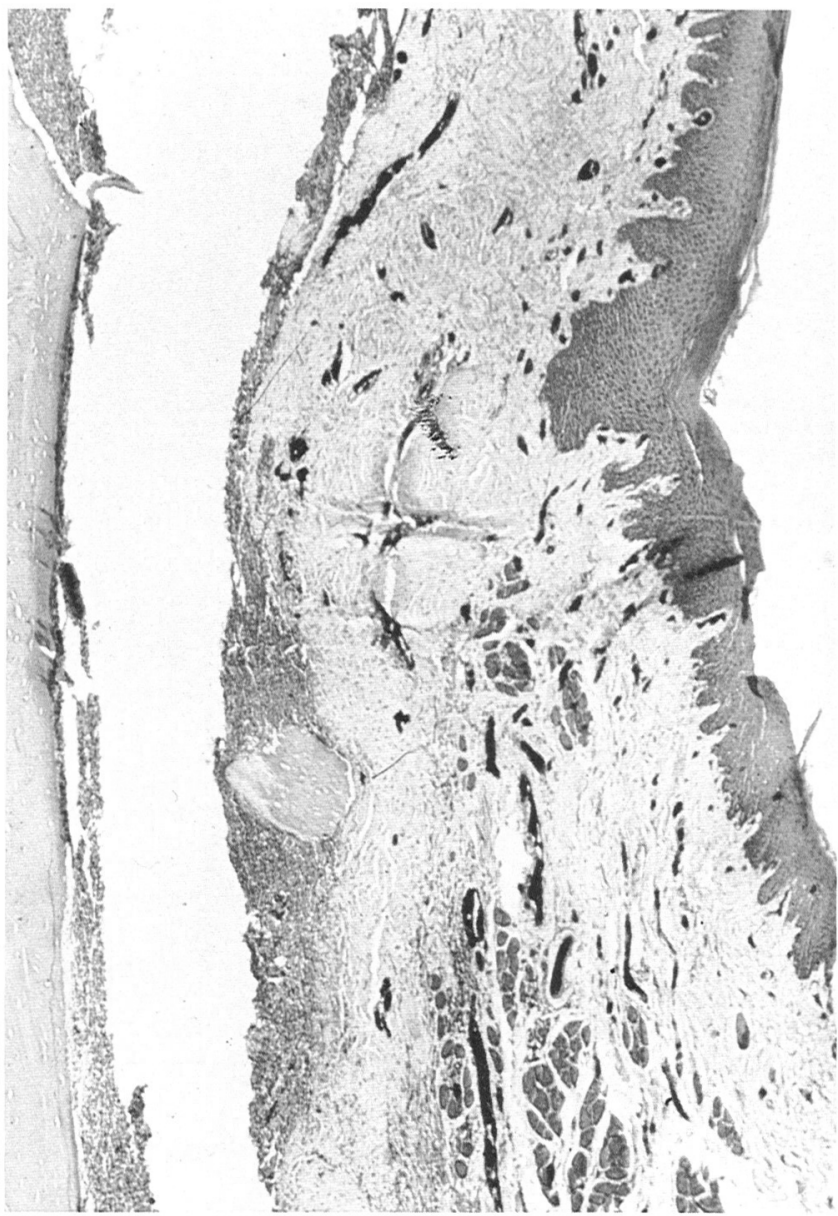

Figure 2. Three-day specimen. A thin blood clot is seen. A bony sequestrum is seen. Perfused vessels are detected throughout $(H \& E$, original magnification $\times 40$ ).
During this time, as well as after the surgical corrections, weekly prophylaxes were provided. Full thickness lateral sliding flaps were performed to cover the recessions following the original technique described by Grupe and Warren. ${ }^{5}$ Prior to surgery and before killing, biometric measurements were taken to determine (1) pocket depth, (2) the amount of gingival recession and (3) the width of the attached gingiva. If the cementoenamel junction (CEJ) was not clearly detected, a notch was used as a reference point.

The animals were killed, providing specimens at 1 , $9,14,21,28$ and 35 days after surgery. A combined solution of Pelikan carbon black and $10 \%$ buffered formalin was perfused through the exposed and can-
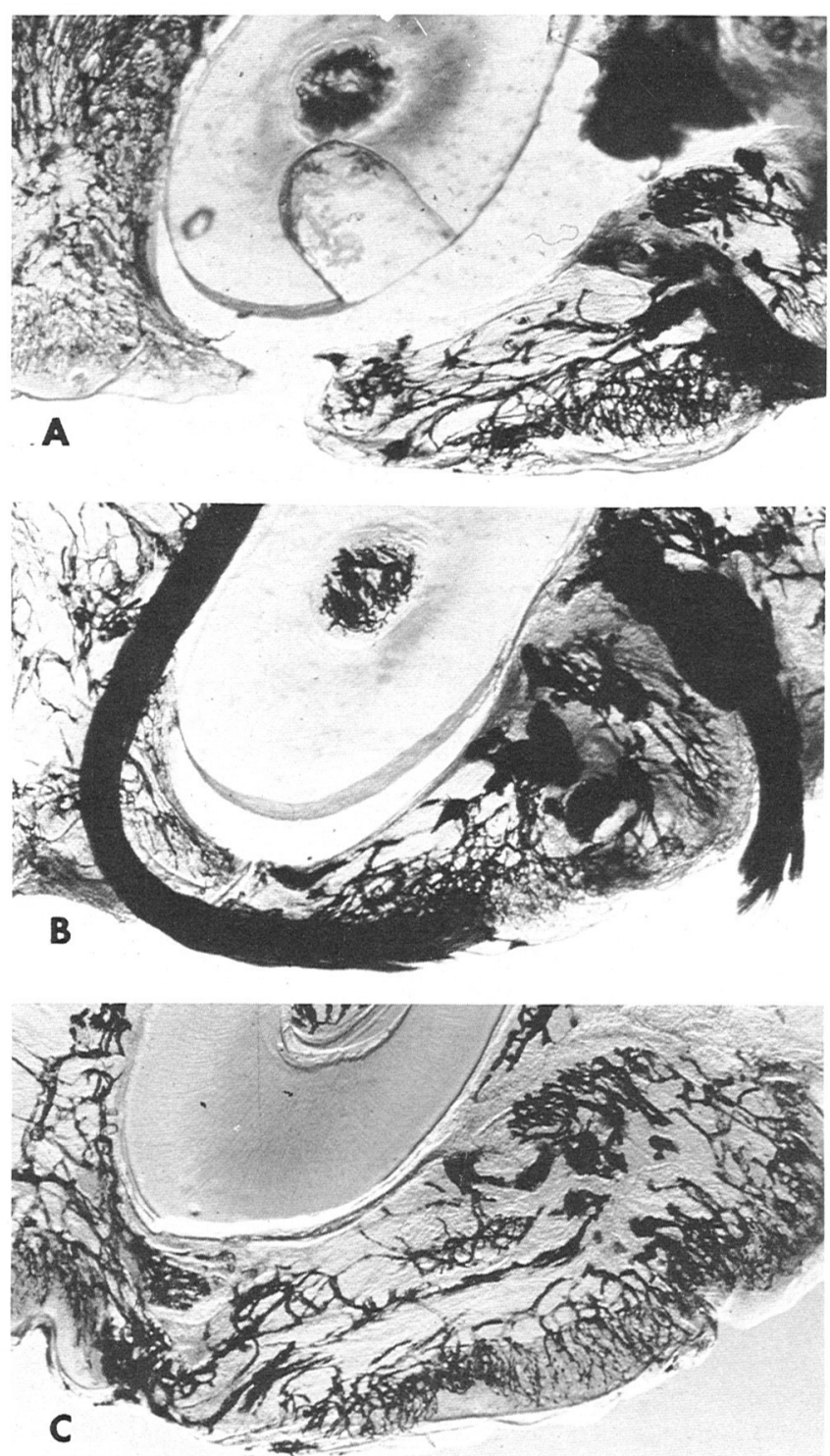

Figure 3. Three-day specimen. A, Level (a)-capillary loops are seen in the flap and the recipient tissues. Extravasation is evident at the tissue interface. B, Level (b)_good flap adaptation to the tooth is seen, C, Level (c)-shows also good adaptation. Similar degree of vascularization is seen in the flap and surrounding tissues (magnification $\times 100$ ). 
nulated external carotid arteries to evaluate revascularization.

After killing, blocks, including the operated teeth and the surrounding tissues, were fixed in $10 \%$ formalin and then decalcified in EDTA. Two teeth per time interval were obtained. One block was processed for regular histological evaluation. Sections were cut at $5 \mu$ bucco-lingually and stained with $\mathrm{H} \& \mathrm{E}$. In these sections, histometric measurements were also recorded to determine the amount of connective tissue attachment and epithelial downgrowth achieved. The other blocks were cut cross-sectionally at about $1-\mathrm{mm}$ thickness. Sections were selected from three different areas: (a) at the most coronal part of the lateral sliding flap, (b) at the middle of the previously existing localized defect and (c) at the bottom of the defect (Fig. 1). These sections were cleared following the Spalteholtz technique ${ }^{6}$ to evaluate the process of revascularization.

\section{RESULTS}

\section{Clinical Evaluation}

Immediately after surgery the tissues, displaced from a neighboring tooth, were secured by simple and sling sutures, covering the recessions and located at or above the CEJ level, even if deep defects were present. The sutures were removed in 7 days. As healing progressed all tissues became less red and shiny, although the vertical boundaries of the flaps were still detectable and the gingival margins were edematous and immature.

Some recession developed up to the 14-day postoperative period, but it remained stable thereafter. The lateral sliding flap appeared to be normal in color, texture and form after 28 days.

A comparison of the mean biometric values recorded before and after the surgery showed a slight increase in pocket depth, a reduction in gingival recession and a gain in attached gingiva (Table 1).

\section{Histological and Microvascular Findings}

One- and Three-Day Specimens. These specimens show a thin blood clot interposed between the flap and the tooth. Dilated and perfused vessels are seen throughout (Fig. 2).

At Level (a) (Fig. 3A) the laterally displaced flap is separated from the recipient margins by a blood clot. Perfused capillary loops can be seen positioned perpendicularly to the outer surface of the displaced flap. Flap and recipient margins depict more vascularization, vaso-dilation and extravasated material than the surrounding tissues. Otherwise, the surrounding structures show normal vascularization. At Level (b) (Fig. 3B) the flap is well adapted to the tooth and recipient margins. The capillary loops are disorganized, vessels are dilated and engorged, and extravasated material is more evident than at Level (a). Less vascularization is observed in the surrounding tissues. At Level (c) (Fig. 3C) no striking difference is seen between the surrounding tissues and the flap vascularization. Intimate adaptation is seen between the flap and the recipient tissues, showing dilated vessels growing also from the periodontal membrane vessels.

Nine-Day Specimens. At Levels (a) and (b), the flap is showing perfusion overall, with increased capillary loops well adapted to the tooth and margins. Vasodilation is still present at the margins, where capillary buds are connecting the two areas (Fig. 4). At Level (c) the capillary network from the surrounding tissues (periodontal membrane, marrow spaces and soft tissue) is nourishing the surgical flap.

Fourteen-Day Specimens. These exhibit an irregular sulcular epithelium with minimal inflammatory infil-

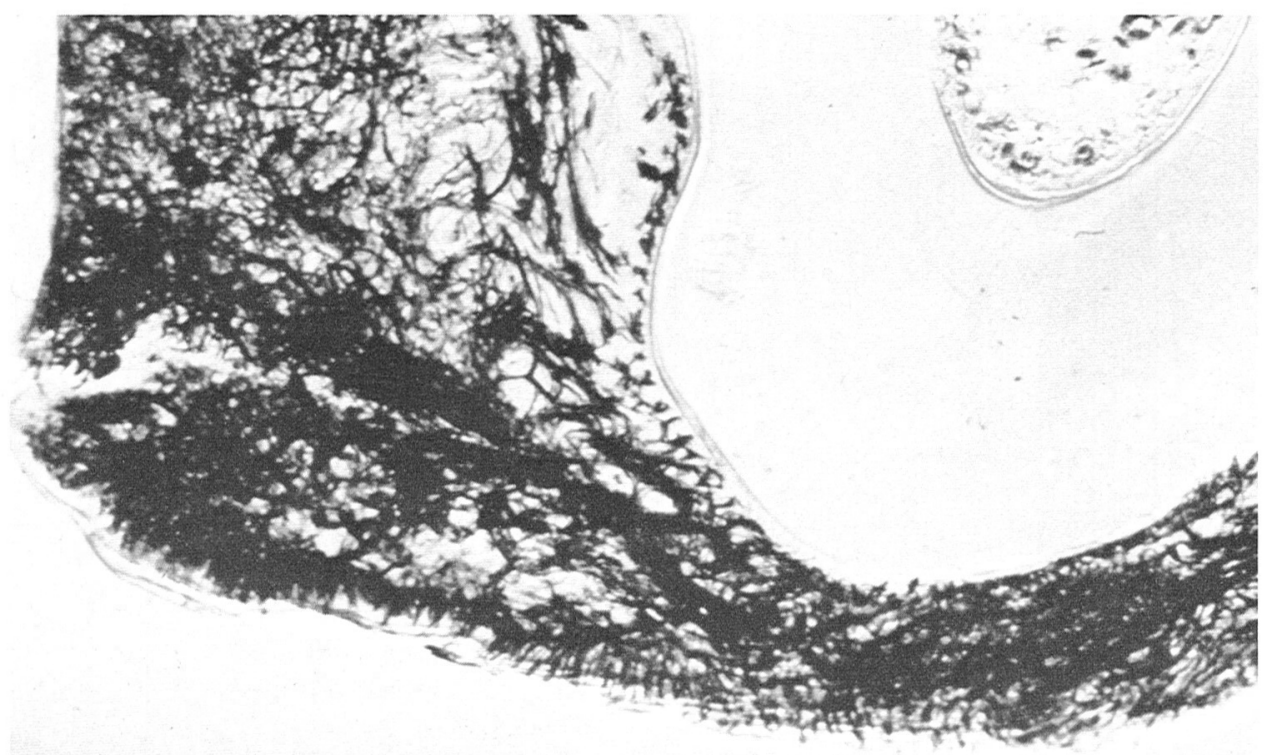

Figure 4. Nine-day specimen. Level (b) increased vascularization with vasodilation is evident throughout. The tissue interface is connected by capillary bands (magnification $\times 100)$. 
trate (Fig. 5). The connective tissue of the wide dentogingival area exhibits some fiber disorganization. A better fiber orientation is present close at the alveolar crest area.

At Level (a) (Fig. 6A) a soft tissue gap is seen at the tooth midline. Increased vascularization is seen at the recipient margins growing from the surrounding tissues including the periodontal membrane. At Level (b) (Fig. 6B) the gap is no longer present and the flap is well adapted to the tooth. Increased vascularity and vessels crossing the margins are seen reconnecting the flap to the recipient site. However, the midline is still lacking good vascularization. At Level (c) (Fig. 6C) the pattern of vascularization is similar in the flap and recipient tissues, with a few engorged vessels at the interface. Heavy vascularization is seen exiting from the periodontal membrane.

Twenty-one-Day Specimens. A thin crevicular epithelium with a light inflammatory reaction is seen (Fig. 7). Connective attachment to the root is seen with bundles of connective tissue fibers running parallel to the tooth, although they show better orientation closer to the alveolar crest. An inflammatory reaction is still present, and resorption on the alveolar crest surface can still be detected.

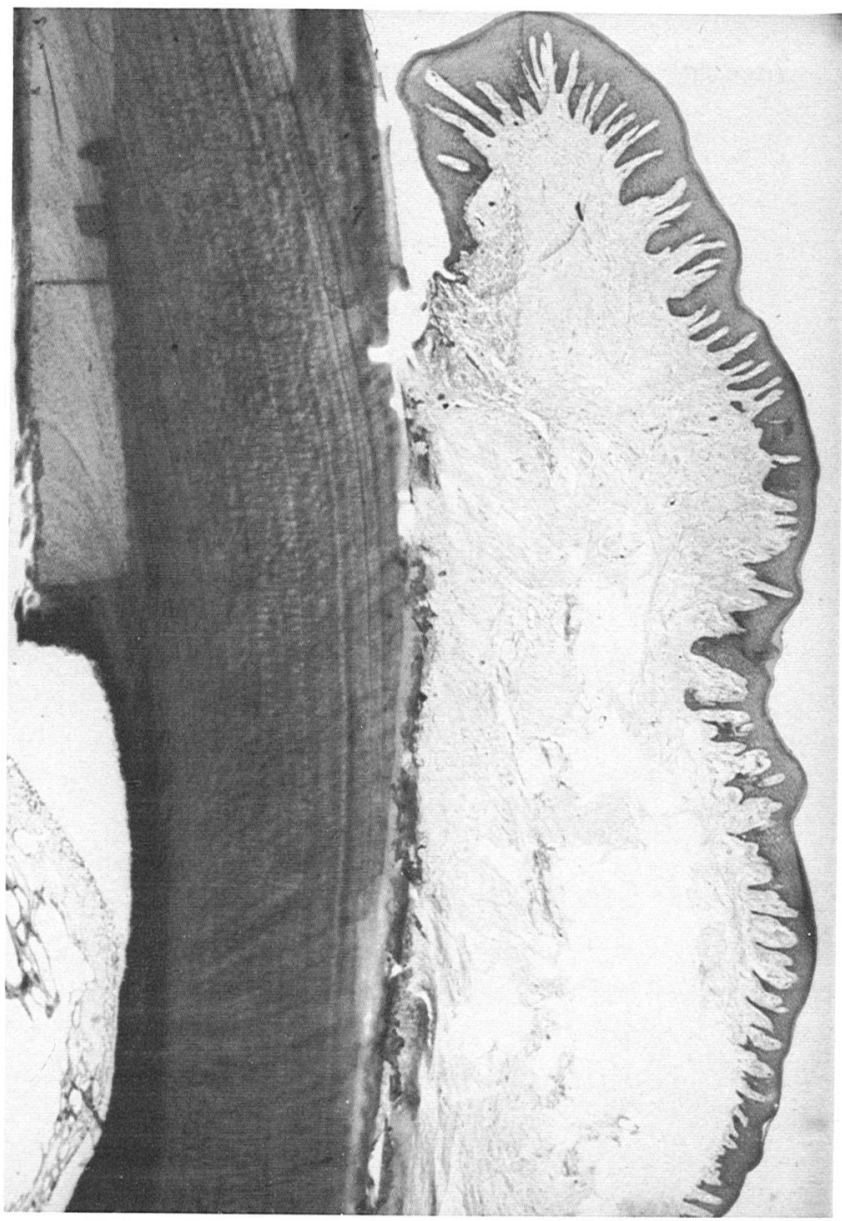

Figure 5. Fourteen-day specimen. Irregular epithelium with inflammation. The connective tissue fibers show some disorganization $(\mathrm{H} \&$ E. original magnification $\times 25$ ).
At Level (a) (Fig. 8A) the flap and the recipient bed are partially separated by a cleft. A thin but well vascularized flap covers the tooth. Vascularity is increased at the margin of the flap, as well as in the periphery of the recipient tissues. At Level (b) (Fig. 8B) perfused vessels are clearly seen crossing the margins of the wound, making the tissue interface almost invisible. There is only a small area where separation is still present. There is an increase in the number of perfused vessels exiting from the periodontal membrane and from the surrounding soft tissues toward the flap. At Level (c) there is an even more advanced healing. The interface is undetectable and increased vascularization is seen affecting all the buccal tissues.

Twenty-eight- and Thirty-five-Day Specimens. Spec-
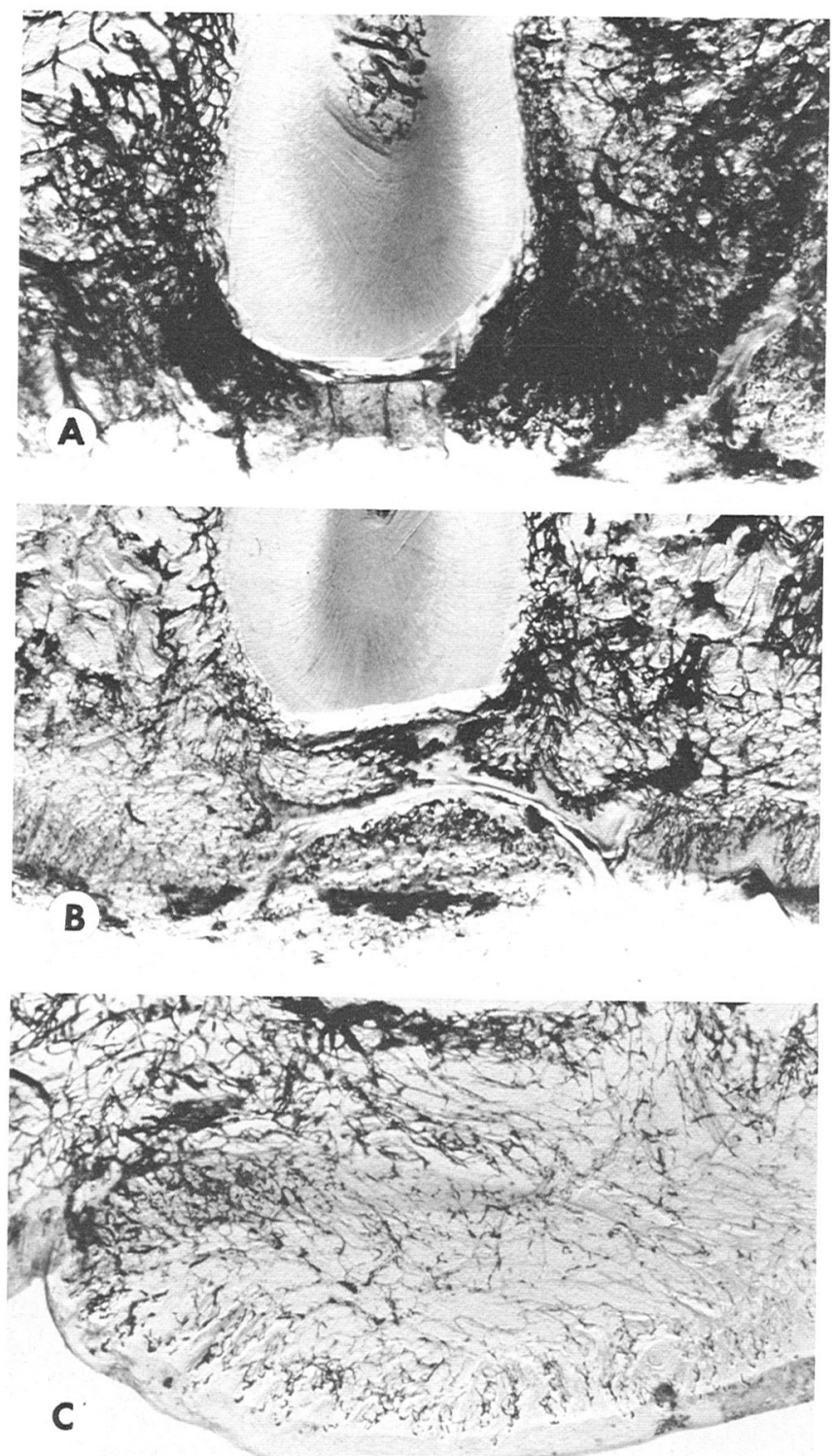

Figure 6. Fourteen-day specimen. A, Level (a)-a gap is present at the midline. Increased vascularization is seen in the recipient margins, including the periodontal membrane. Buds are starting to bridge the gap. B, Level (b)-good coverage is present. C, Level (c)-shows increased vascularization exiting from the periodontal membrane (magnification $\times 100$ ) 
imens show a thin, long, junctional epithelium traveling a variable distance towards the bottom of the created defect (Fig. 9A). The inflammatory reaction is mild, mainly present at the gingival margin. The fiber arrangement at the marginal area is normal. The root is partially devoid of cementum, but the fibers show good adaptation and apparent attachment to the root (Fig. 9B). There is still some mild inflammatory reaction at the alveolar crest.

At 28 days the papillae have reestablished vascularization at the healing interface at Level (a) (Fig. 10A); however, the margin has receded and is apically located. At Level (b) (Fig. 10B) the flap is covering the root. The vascularization is still increased at the midline where healing is still going on. At Level (c) (Fig. 10C) the vessels show reduced patency in the flap and surrounding tissues. The vessels exiting from the periodontal membrane are still increased.

At 35 days the flaps show good coverage of the area at the three levels ( $a, b$ and $c)$. The patency of the vessels is reduced, especially at Level (c), being similar in the flap and the neighboring tissues (Figs. 11 A-11C).

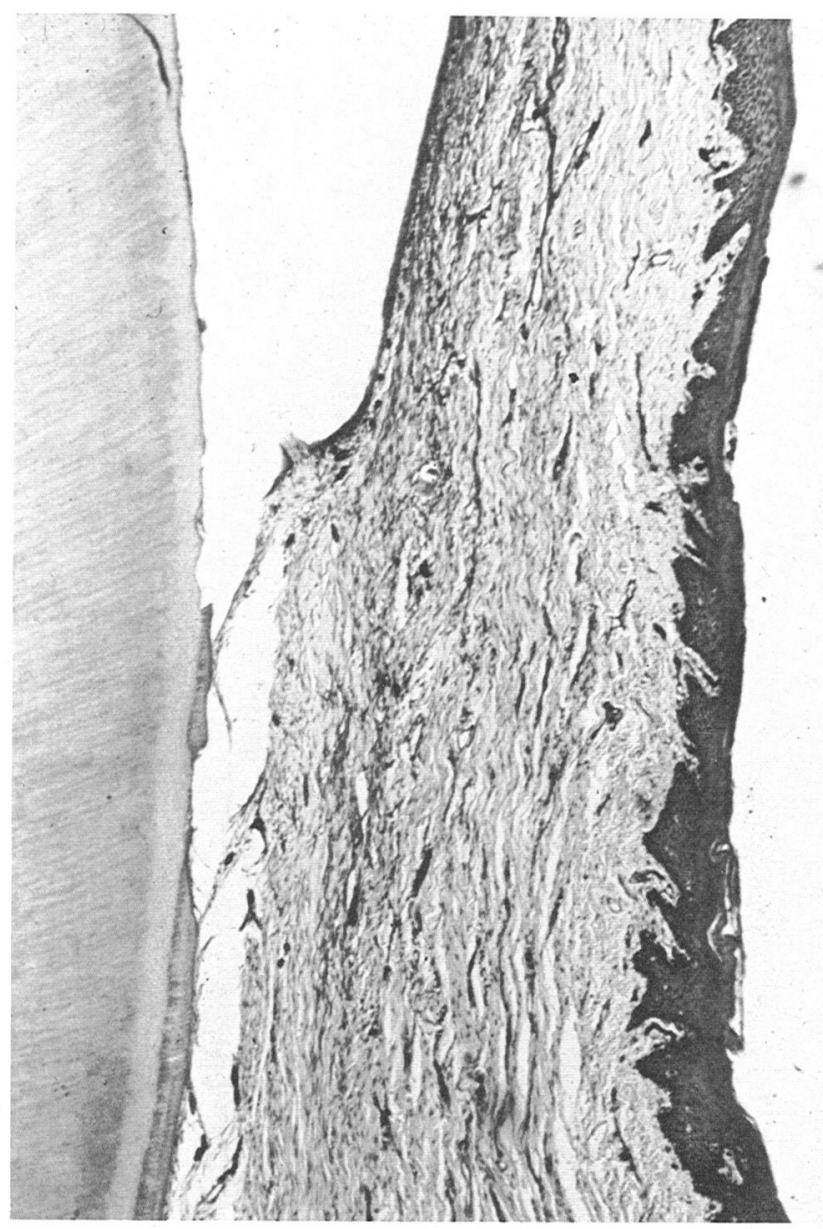

Figure 7. Twenty-one-day specimen. A thin junctional epithelium and new connective tissue attachment to the root has developed. The fibers depict a course parallel to the root $(H \& E$, original magnification $\times 40)$.
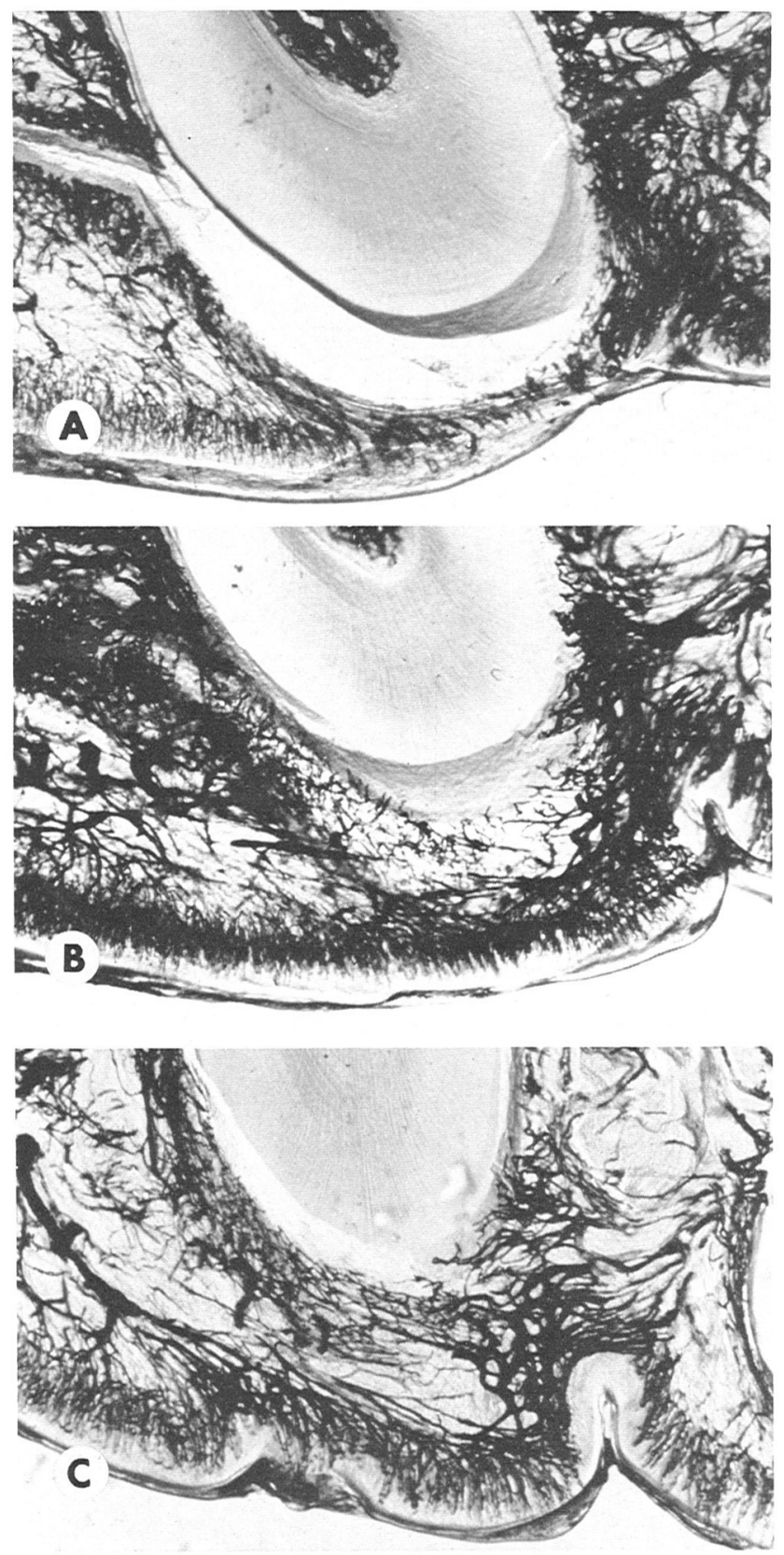

Figure 8. Twentv-one-day specimen. A, Level (a)-a thin flap covers the root. A cleft still separates the flap from the recipient bed. B, Level (b)-increased vascularization is seen throughout the periphery of the flap and the bed. The interface is getting indistinct. C, Level (c)advanced healing. Observe the increased vascularization in the periodontal membrane (magnification $\times 100)$.

\section{Histometric Evaluation}

Histometric measurements recorded at 21, 28 and 35 days indicate that roughly between 40 to $50 \%$ of the coverage achieved is mediated by connective tissue, while the remaining 50 to $60 \%$ is due to epithelial downgrowth (Table 2).

\section{DISCUSSION}

The results indicate that by 21 days revascularization of the flap can be reestablished. The vessels in the 
transplanted flap maintain patency and contribute to the reestablishment of vascular anastomoses. The sources for repair from the recipient tissues are represented by the soft-tissue bed, the bone marrow and also the periodontal membrane. Actually, the periodontal vascularization shows increased flow even after 28 days. These vessels significantly contribute to the reestablishment of the vascularization of the transposed tissues especially in that area of the recession that is located farthest from the alveolar crest. This may explain why the papillary bed has been described as being so important in the success of these procedures. ${ }^{8}$ The more papillary bed the more periodontal membrane will be exposed by the surgical procedure away from the bottom of the recession.

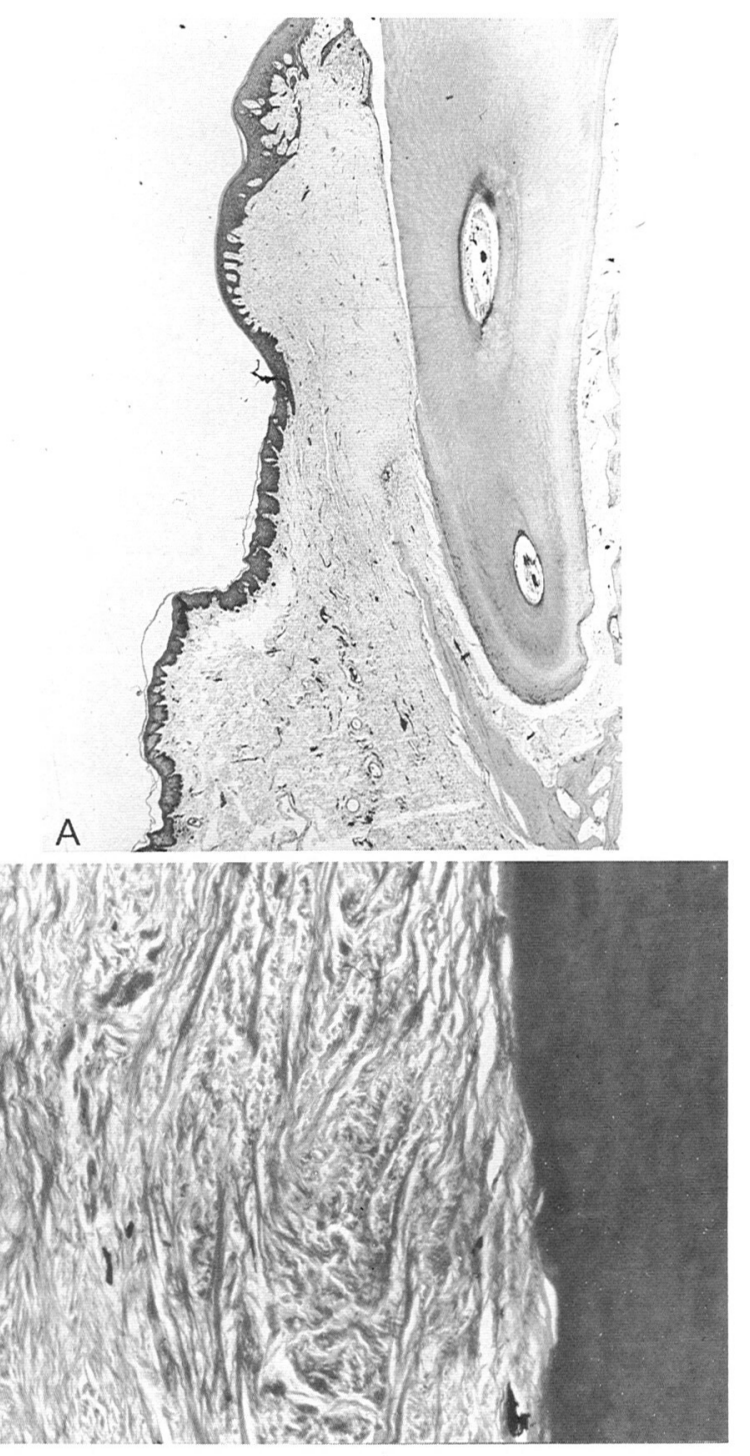

Figure 9. Twenty-eight-day specimen. A, a long junctional epithelium mediates the marginal seal. Connective tissue attachment is seen underneath $(H \& E$, original magnification $\times 10)$. $\mathbf{B}$, higher magnification showing the fibrous attachment to the root. Cementum has been removed. Good connective tissue adaptation and supposedly attachment is seen. The fibers are running mainly parallel to the root ( $H \&$ E, original magnification $\times 250$ ).
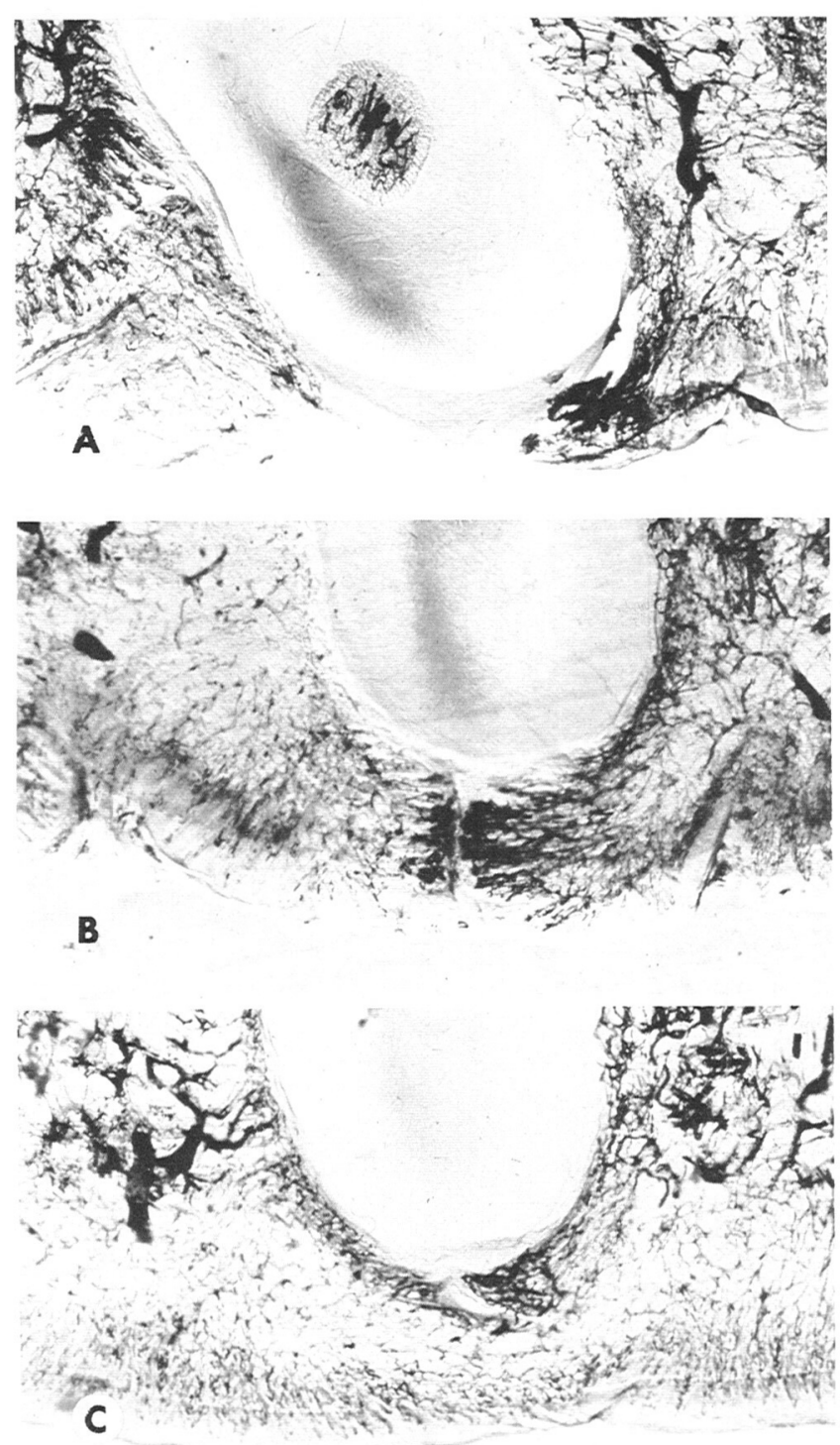

Figure 10. Twenty-eight-day specimen. A, Level (a)-revascularization is reestablished in the papillae but the gingival margin has receded. B, Level (b)-good root coverage is seen, but the vascularization is increased at the midline where healing is still incomplete. $\mathbf{C}$, Level (c)-reduced vascularization is depicted in the tissues; however, the vessels growing from the periodontal membrane are still increased (magnification $\times 100$ ).

The present results completely agree with those reported by Wilderman and Wentz ${ }^{1}$ in dogs. Fifty per cent of the created recession was covered, and of the coverage obtained, roughly $50 \%$ corresponded to connective tissue attachment and $50 \%$ to a long junctional epithelium. One-half of the created defects were not repaired due either to atrophy or displacement of the flaps. The present results also agree with those reported by Pfeifer and Heller ${ }^{2}$ when a full-thickness mucoperiosteal flap was used. A lateral sliding flap showed connective tissue reattachment along the apical onehalf of the coverage achieved. Similar findings were reported by Sullivan et al. ${ }^{3}$ and Sugarman ${ }^{7}$ in humans.

No definite evidence of cementum deposition was 

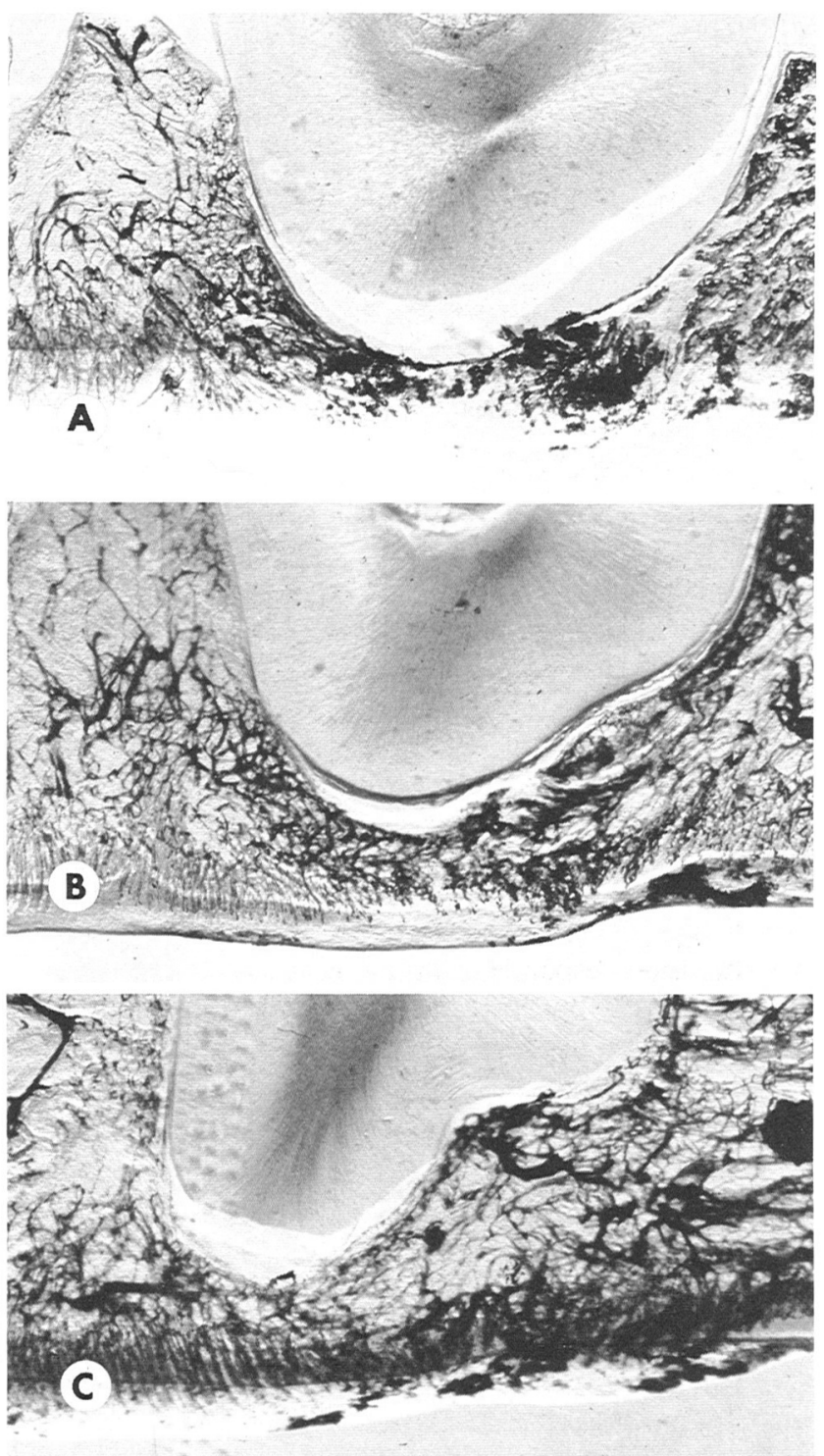

Figure 11. Thirty-five-day specimen. A, Level (a)-revascularization is complete, but localized areas of dilation are still present. B, Level (b) -the pattern of vascularization is evenly distributed throughout the flap and recipient tissues. $\mathbf{C}$, Level (c)-observe the reduced vascularization arising from the periodontal membrane (magnification $\times 100$ ).

seen in the present study at any period of observation. However, good adaptation of the connective tissue to the roots was the rule. It is possible that if observation times were extended, cementum would have deposited on the covered roots in areas facing connective tissue. It is reemphasized that the purpose of this study was to evaluate revascularization and the contribution of the periodontal membrane vessels. Recessions were created and remained exposed for only 2 months. It may be that this waiting period did not represent enough time for the exposed roots to become completely contaminated, which may have altered the results achieved. ${ }^{1}$
Table 2

Mean Histometric Values

\begin{tabular}{lcccc}
\hline No. of days & $\begin{array}{c}\text { Epithelial down- } \\
\text { growth }\end{array}$ & \multicolumn{2}{c}{ Connective tissue } \\
\hline 21 days & 6.98 & $49 \%$ & 6.55 & $51 \%$ \\
28 days & 4.98 & $58 \%$ & 3.65 & $42 \%$ \\
35 days & 5.18 & $56 \%$ & 4.14 & $44 \%$ \\
& & & & \\
Total & 5.41 & $56 \%$ & 4.78 & $44 \%$ \\
\hline
\end{tabular}

On the other hand, the surgical wounds were not protected at all postoperatively, which may account for the achievement of only $50 \%$ coverage.

\section{CONCLUSIONS}

Within the limits of this study it can be concluded that:

1. By 21 days, a definite vascular network is reestablished in the surgical area.

2. The vessels in the flap maintain their patency after surgery and contribute to healing.

3. Anastomoses at the surgical interface are reestablished with capillaries arising from the recipient soft tissue bed, bone marrow and periodontal membrane.

4. Vessels from the periodontal membrane contribute significantly to the reestablishment of the vascular network.

5. The new connection of the tissues to the root involves both connective tissue attachment and a long junctional epithelium.

\section{REFERENCES}

1. Wilderman, M., and Wentz, F.: Repair of a dentogingival defect with a pedicle flap. $J$ Periodontol 35: 218, 1964.

2. Pfeifer, J., and Heller, R.: Histologic evaluation of full and partial thickness lateral repositioned flaps: a pilot study. J Periodontol 42: $331,1971$.

3. Sullivan, H., Carman, D., and Dinner, D.: Histological evaluation of the laterally positioned flap (Abstr. 467). Int Assoc Dent Res, 1971.

4. Listgarten, M.: Electron microscopic study of the junction between surgically denuded root surfaces and regenerated periodontal tissue. J Periodont Res 7: 68, 1972.

5. Grupe, H., and Warren, R.: Repair of gingival defects by a sliding flap operation. J Periodontol 27: 92, 1956.

6. Spalteholtz, W.: Die Arterien der Herzwand, p 13. Leipzig, S. Hirzel, 1924.

7. Sugarman, E.: A clinical and histological study of the attachment of grafted tissue to bone and teeth. J Periodontol 40: 381, 1969.

8. Guinard, E. A., and Caffesse, R. G.: Treatment of localized gingival recessions. Part III. Comparison of results obtained with lateral sliding and coronally repositioned flaps. J Periodontol 49: 457, 1978.

Send reprint requests to: Dr. Raul G. Caffesse, Department of Periodontics. The University of Michigan School of Dentistry, Ann Arbor, MI 48109. 